\title{
A scoping review of the analytical literature concerning nonambulatory dairy cattle
}

\author{
W. J. McFarlane, $\odot$ D. L. Renaud, $\odot$ C. N. Reedman, $\odot$ T. F. Duffield, $\odot$ M. B. Van Camp, $\odot$ and C. B. Winder* $\odot$ \\ Department of Population Medicine, University of Guelph, Ontario, Canada N1G 2W1
}

\begin{abstract}
Nonambulatory dairy cattle pose a complex problem due to the challenges associated with prevention, appropriate treatment and management, and arriving at an accurate prognosis. There is a breadth of literature regarding this topic, of which there is currently no formal synthesis. The objective of this scoping review was to describe and characterize the literature investigating risk factors, sequela, preventions, treatments, and prognostic factors for nonambulatory conditions in dairy cattle, with the intent of qualitatively synthesizing knowledge of the topic and identifying gaps in the literature. A literature search was conducted in 6 databases and 2 conference proceeding archives, which returned 7,568 unique articles. Initial screening of abstracts resulted in 1,544 articles reviewed at the full-text stage, of which 379 were included for data extraction. Over $75 \%$ of the included literature was published after 1980, and the most common countries in which these studies took place were the United States $(\mathrm{n}=72)$, Canada (18), Sweden (17), and Germany (17). Common eligibility criteria used for inclusion were geographic region (97) and parity (92). Of the 379 studies included in this review, 144 were randomized controlled trials and 235 were observational studies. The majority of the controlled trials assessed prevention of nonambulatory conditions (116), most commonly through supplementation of vitamin D (27) and calcium (25) or the provision of anionic salts (22). Of the 28 studies focusing on treatment of nonambulatory conditions, 26 focused on calcium administration. Becoming nonambulatory was evaluated as an outcome in 165 of the observational studies. Frequently measured risk factors for becoming nonambulatory included hematological variables, such as blood calcium (73), phosphorus (53) and magnesium (42), and other factors such as parity (35) and breed (22). Recovery from a nonambulatory condition was
\end{abstract}

Received July 21, 2021.

Accepted November 4, 2021.

*Corresponding author: winderc@uoguelph.ca the outcome in 31 of the observational studies, with commonly measured prognostic indicators being calcium (9), phosphorus (9), and duration of recumbency (7). Nonambulatory disorders were measured as risk factors in 53 of the observational studies, with the most commonly assessed outcomes including disorders of the transition period (11), and death or euthanasia (11). The most common terms used to describe nonambulatory conditions were "milk fever" (199) and "parturient paresis" (147). These terms were only further defined with explicit symptomatic criteria in 193 of the 379 studies in this review. Recumbency was the most commonly used of these criteria (144), followed by inability to rise (55). Potential gaps in the literature concerning nonambulatory dairy cattle that were identified in the present review included investigation of prognostic indicators for recovery from nonambulatory conditions that are applicable on farm, treatment alternatives to calcium administration, and guidance regarding the appropriate usage of terms meant to categorize nonambulatory dairy cattle.

Key words: downer cow, nonambulatory cow, prognostic indicator, scoping review

\section{INTRODUCTION}

Dairy cattle that become nonambulatory pose a plethora of challenges to the dairy industry, which are further complicated by the variation in prognostic factors used to inform treatment and euthanasia of these animals. Approximately $70 \%$ of dairy operations in the United States reported one or more nonambulatory dairy cattle in 2014 (USDA, 2018). Although national statistics regarding all nonambulatory conditions experienced by dairy cattle are not currently available in other countries, herd-level prevalence of recumbency in dairy cattle due to acute hypocalcemia has been estimated to be 3\% in Ireland (Mee, 1993), $7.7 \%$ in the United Kingdom (Esslemont and Kossaibati, 1996), and between $1.6 \%$ and $5.4 \%$ in Australia (Caple, 1987). Nonambulatory dairy cattle also represent a welfare concern, as both the proximate reason for recumbency and recumbency itself can be painful (Cox and Onap- 
ito, 1986; Mulon, 2013), and inappropriate methods of moving these animals can result in further injury (Blonde and Leder, 2016). Moreover, nonambulatory dairy cattle pose a financial burden on producers when provision of veterinary care is required (Fikadu et al., 2016), as well as following the cow's recovery, as these cattle can have decreased milk production (Bar and Ezra, 2005) and a reduced productive lifespan (Khan et al., 2015).

Cattle become recumbent for a variety of reasons including metabolic imbalances such as hypocalcemia and hypomagnesia (Allen and Davies, 1981), traumatic injuries such as fractures (Yadav et al., 2019), and nerve damage following dystocia (Poulton et al., 2019). The cause of recumbency can also be multifactorial, such as cattle originally recumbent due to metabolic imbalances that experience pressure damage or become injured as a result of unsuccessful attempts to rise (Cox, 1988). Less common causes of recumbency include infectious disease (Braun et al., 2005) and ingestion of toxic substances (Bradley, 1993). Regardless of the primary cause of recumbency, the prognosis worsens the longer a cow is recumbent. This is due to the onset of secondary muscular damage (Poulton et al., 2016a), often taking the form of nerve damage and ischemic necrosis of muscle tissue (Cox et al., 1982). The odds of recovering from a nonambulatory condition decrease 3-fold after $24 \mathrm{~h}$ of recumbency (Green et al., 2008). Therefore, it is important that producers and veterinarians arrive at a rapid and accurate diagnosis and treatment plan for nonambulatory dairy cattle.

The decision-making process for managing nonambulatory dairy cattle is complicated by a broad and complex body of literature regarding the effectiveness of prognostic indicators in predicting the recovery of nonambulatory cattle, of which there is currently no formal synthesis. Although narrative reviews covering the topic of nonambulatory dairy cattle have been published (Hibbs, 1950; Thilsing-Hansen et al., 2002; DeGaris and Lean, 2008), these types of reviews may be less thorough and more subjective compared with reviewing processes that follow a formal methodology (Schmidt and Gotzsche, 2005). A formal synthesis of the literature regarding nonambulatory dairy cattle could help guide future research efforts by identifying gaps in the literature and providing a valuable preliminary step toward conducting a systematic review on this topic. The objective of this scoping review is to describe and characterize the literature investigating risk factors, sequela, preventions, treatments, and prognostic factors for nonambulatory conditions in dairy cattle, with the intent of qualitatively synthesizing knowledge of the topic and identifying gaps in the literature.

\section{MATERIALS AND METHODS}

This scoping review followed the methodological framework outlined by Arksey and O'Malley (2005) and the reporting guidelines of the Preferred Reporting Items for Systematic Reviews and Meta-Analysis (PRISMA)-ScR extension for scoping reviews (Tricco et al., 2018).

\section{Protocol Registration}

The protocol for this scoping review was developed a priori and has been stored in The Atrium, a data repository at the University of Guelph (http://hdl.handle .net/10214/17820).

\section{Eligibility Criteria}

Primary literature and conference proceedings were eligible for inclusion in this scoping review, provided they described an analytical study in which becoming nonambulatory was a measured risk factor or outcome in a population of dairy cattle. Furthermore, studies were only eligible to be included if a full-text copy of the publication was available online, was in English, and exceeded 500 words. No restrictions were placed regarding geography or date of publication.

\section{Information Sources}

The literature search involved 6 databases that were chosen based on their likelihood of containing publications involving nonambulatory dairy cattle as follows: AGRICOLA (via ProQuest), Web of Science, CABI (via CAB direct), SCOPUS, ProQuest Theses and Dissertations, and Medline (via Web of Science). Additionally, available archived conference proceedings from the World Buiatrics Congress (conference proceedings from 2002 to 2018 archived on the IVIS website) and the American Association of Bovine Practitioners (conference proceedings available from 2013 to 2018 archived on the AABP website) were searched for relevant literature.

\section{Literature Search}

To maximize sensitivity, a search string was developed with the intent of capturing all the ways an author could choose to refer to nonambulatory cattle. This was achieved by combining the following 3 search strings: the first containing relevant synonyms for the term "nonambulatory," the second containing relevant synonyms for cattle, and the third containing phrases 
Table 1. Search strings used to capture literature relating to nonambulatory dairy cattle in 6 databases ${ }^{1}$ during the literature search conducted for the present scoping review on March 20, 2020

\begin{tabular}{ll}
\hline Item & Search string \\
\hline 1 & Nonambulatory OR "non ambulatory" OR ambulatory OR downer OR recumbent OR recumbency OR Immobile OR "Unable to \\
2 & Stand" OR "Unwilling to stand" OR paralysis OR paralyzed \\
3 & "ow* OR Bovine OR Cattle OR "Bos Taurus" OR Bovinae OR Heifer* \\
4 & (1 AND 2) OR 3
\end{tabular}

${ }^{1}$ AGRICOLA, CABI (via CAB direct), Medline, Proquest theses and dissertations, Web of Science, and SCOPUS, and conference proceedings from the World Buiatrics Congress (2002-2018) and the American Association of Bovine Practitioners (2013-2018).

used colloquially by producers and veterinarians to describe nonambulatory cattle (Table 1). By linking terms within the search strings with the operator "or," and linking the nonambulatory search string and the cattle search string with the operator "and," this component of the search string aimed to capture all studies that used any of the terms in the nonambulatory search string as well as any of the terms in the cattle search string. The third component of the search string included phrases such as "down cattle," to avoid the inclusion of irrelevant literature that would result from including "down" in the nonambulatory search string. A preliminary test of the search terms was conducted in the database CABI (via CAB direct) to help ensure that these terms were suitable to capture the body of literature we intended to synthesize. The final search string used in the literature search is described in Table 1 .

\section{Study Selection}

All results from the literature search were imported to EndNote version X9 (Clarivate Analytics) where duplicate studies were removed, then imported into DistillerSR (Evidence Partners Inc.) to remove remaining duplicates and complete the 2-phase screening process. The screening process was conducted by 2 graduate students from the University of Guelph (authors W. J. McFarlane and M. B. Van Camp), 2 undergraduate students from the University of Guelph (Derrick Knill and Andrea Bajus), and 1 veterinary student (Kineta Cousins). During the first screening phase, the title and abstract of each study was screened based on the following questions:

1. Is the title/abstract available in English?

2. Does the title/abstract describe primary research?

3. Does the title/abstract describe a study involving mature dairy cattle that are unable to stand?

Two reviewers independently answered each question as "yes," "no," or "unclear." Only articles that received an answer of "yes" or "unclear" for all 3 questions moved on to the next phase of screening. Exclusion was at the form level, with both reviewers answering "no" to any of the 3 questions resulting in exclusion of the article. Disagreement between the 2 reviewers was resolved by consensus, with mediation by D.L.R. and C.B.W. when consensus could not be reached. A pretest of the first 100 articles was performed to ensure all reviewers understood the questions and how to apply them appropriately in the screening process.

For the second phase of screening, the full-text articles of studies meeting the criteria of phase 1 were obtained and subjected to additional screening based on the following questions:

1. Does the full text describe primary research?

2. Is the full text available in English?

3. Is the full text more than 500 words?

4. Does the full text describe a study involving mature dairy cattle that are unable to stand?

5. Does the full text describe an analytical study?

Two reviewers independently answered "yes" or "no" to each question, with an answer of "yes" to all 5 questions resulting in inclusion. Exclusion was at the question level, with an article only being excluded if both reviewers responded "no" to the same question. As in phase 1, disagreement between the 2 reviewers was resolved by consensus, with mediation by D.L.R. and C.B.W. when consensus could not be reached. A pretest of the first 10 articles was performed to ensure all reviewers and mediators understood the form.

\section{Data Extraction}

Data from all articles included after the second phase of the screening process were extracted independently by authors W.J.M. and C.N.R. using a data extraction form in DistillerSR. Disagreement between the reviewers was resolved by consensus, with mediation by D.L.R. and C.B.W. when consensus could not be reached. A pretest of the data extraction form was performed on the first 10 articles to ensure all review- 
ers and mediators understood the form. Data extracted from the full-text articles include the following:

1. General study characteristics (year the study was conducted and published, hypothesis and objective)

2. Population characteristics (country of study, type of farm, breed, housing type)

3. General study design (sample size, number of farms, unit of interest, eligibility criteria, study type)

4. Questions specific to study type

a. Randomized controlled trial (type of trial, randomization strategy, type of intervention, treatment groups, outcome definition, period of risk of developing outcome)

b. Cross-sectional study (whether being nonambulatory was an outcome or risk factor, list of exposures, list of outcomes, whether data were collected at a single point in time)

c. Cohort study (whether being nonambulatory was a risk factor or an outcome, list of exposures, list of outcomes, whether the study was prospective or retrospective)

d. Case-control study (case definition, control definition, sourcing of controls, whether being nonambulatory was a risk factor or an outcome, list of exposures and list of outcomes)

\section{Synthesis of Results and Charting}

Data extraction forms were imported into Microsoft Excel 16.0 (Microsoft Corp.), where extraneous data were removed before importing the results into Microsoft Word 16.0 (Microsoft Corp.) as a table. Once tabulated, data were cleaned by converting responses into a concise format with consistent vocabulary to aid the indexing and enumeration of study attributes. The flowchart illustrating the screening process (Figure 1), the table summarizing the data extraction (Supplemental File: https://doi.org/10.5683/SP2/JHWCMF), and framework for this scoping review were guided by the PRISMA extension for scoping reviews (Tricco et al., 2018).

\section{RESULTS}

\section{Included Studies}

The literature search carried out on March 20, 2020, yielded 12,279 articles as follows: 5,712 identified in CABI (via CAB direct), 2,564 in SCOPUS, 1,660 in Medline, 1,546 in Web of Science, 702 in AGRICOLA, and 55 in ProQuest theses and dissertations. The literature search also returned 40 conference proceedings from the World Buiatrics Congress (conference proceedings from 2002-2018) and the American Association of Bovine Practitioners (conference proceedings available from 2013-2018). After the removal of duplicates, the abstracts of 7,568 unique articles were reviewed, resulting in 1,544 articles eligible for full-text screening, of which 379 were included for data extraction (Figure 1).

\section{General Study Characteristics}

When the included articles were grouped by decade of publication, the frequency of publication on nonambulatory dairy cattle appeared to have increased over time, from 2 publications in the 1930s to 103 publications in the 2010s, the majority of this literature being published after 1980 (Figure 2). The year the study was conducted was reported in less than half of the studies $(\mathrm{n}=171 / 379 ; 45 \%)$. The study objective was stated explicitly in $83 \%$ of studies $(314 / 379)$, whereas the study hypothesis was stated in only $13 \%$ of studies (48/379).

\section{Population Characteristics}

The country in which the study was conducted was reported in $65 \%$ of studies $(247 / 379)$, with the most common study locations being the United States $(72 / 247 ; 29 \%)$, Canada $(18 / 247 ; 7 \%)$, Sweden $(17 / 247$; $7 \%)$, Germany (17/247; 7\%), and Australia (14/247; $6 \%$; Figure 3 ). Of the 236 studies reporting the type of farm used, $74 \%$ were conducted in commercial farms (174/236), 21\% reported using research herds (50/236), and $5 \%$ reported using both research and commercial herds $(12 / 236)$. Breed of the cattle involved in the study was reported in $78 \%$ of studies $(295 / 379)$. The most common breed reported was Holstein (214/295; $73 \%$ ), followed by Jersey $(77 / 295 ; 26 \%)$. Nine percent of studies reported that they used crossbred cattle $(26 / 295)$. Less common breeds reported in the literature included Ayrshire, Guernsey, Simmental, Swedish Red, and Swedish Red and White. Of the studies reporting breed, 35\% (103/295) of studies reported using more than 1 breed of dairy cattle in their study. Housing type was reported in $32 \%$ of studies, (120/379); $49 \%$ of these studies reported using freestalls (59/120), 38\% reported using tiestalls (46/120), and 33\% reported that animals were housed on pasture $(39 / 120)$.

\section{General Study Design}

Sample size of studies ranged from 5 to over 8 million study units, with a median sample size of 2,197 study units; the unit of interest was the individual 
cow in $96 \%$ of studies $(365 / 379)$ and the herd in $4 \%$ of studies (14/379). The sample size of the majority of studies ranged from 11 to 100 (191 studies), but the distribution was highly right skewed, with 27 studies having sample sizes exceeding 10,000, 13 having sample sizes exceeding 100,000 , and 2 having sample sizes exceeding 1,000,000 (Figure 4). The right-skewed sample size distribution could be explained in part by the fact that 42 of the individual-level studies reported their sample size as number of calvings or lactations, indicating that 1 cow could contribute multiple data points over the duration of the study. Only $55 \%(201 / 365)$ of the individual-level studies reported the number of farms involved. The number of farms involved in studies where analysis was at the cow level ranged from 1 to over 19,000, with a median of 10 farms. Of the studies that reported the number of farms used, the majority reported using 10 farms or less $(129 / 201 ; 64 \%)$, and many reported having used 1 farm $(81 / 201 ; 40 \%)$. Figure 1 depicts the distribution of observational studies and randomized controlled trials in the present review, as well as the type of observational studies and the nature of the interventions used in controlled trials.

The most common eligibility criterion for a cow to enter a study was geographic region $(97 / 320 ; 30 \%)$, where the author indicated that only herds in a specific location were eligible for inclusion. The next most common inclusion criterion was parity $(92 / 320 ; 29 \%)$. Notable differences were found in the use of parity and region as eligibility criteria in the controlled trial literature compared with the observational study literature. Specifically, parity was more commonly included in the eligibility criteria for the controlled trial literature $(70 / 115 ; 61 \%)$ compared with the observational literature $(22 / 205 ; 11 \%)$, whereas region was a more
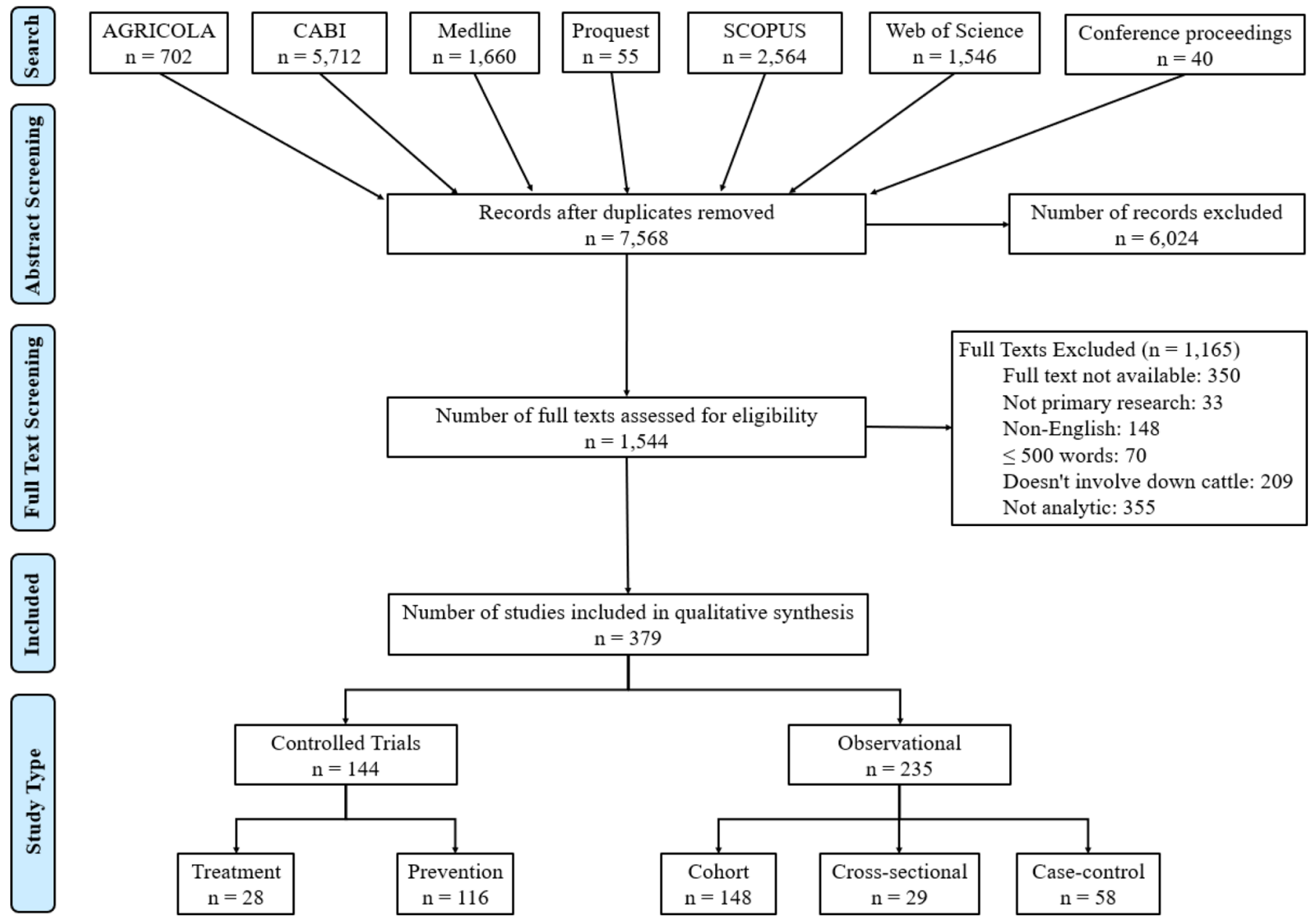

Figure 1. A Preferred Reporting Items for Systematic Reviews and Meta-Analysis (PRISMA) flowchart describing the literature search, screening process, and distribution of study type of the results of this scoping review, which intended to characterize the analytical literature investigating nonambulatory conditions in dairy cattle (Tricco et al., 2018). 
common eligibility criteria among the observational literature $(96 / 205 ; 47 \%)$ compared with the controlled trial literature $(1 / 115 ; 1 \%)$.

\section{Nonambulatory Terminology}

The most common labels given to nonambulatory outcomes and risk factors were "milk fever" $(199 / 379 ; 53 \%)$ and "parturient paresis" (147/379; 39\%). Less common terms used included "downer cow syndrome," or simply "downer cow," which was used in $12 \%$ of the literature (47/379), and "nonparturient paresis" (10/379; 3\%). A notable portion of the literature $(59 / 379 ; 16 \%)$ enrolled only nonambulatory dairy cows in their study and used recovery from a nonambulatory condition as their study outcome. The cumulative frequency of nonambulatory terms (461) exceeded the number of studies included in the present review (379) because several studies used multiple nonambulatory terms interchangeably.

Explicit symptomatic criteria were only used in $51 \%(193 / 379)$ of the included studies. Recumbency was the most commonly used diagnostic criterion $(144 / 193 ; 75 \%)$, followed by inability to rise $(55 / 193$; $28 \%)$, comatose $(10 / 193 ; 5 \%)$, paralysis $(8 / 193 ; 4 \%)$, and ataxia $(5 / 193 ; 3 \%)$. Explicit definitions of recovery were only reported in $63 \%(37 / 59)$ of the studies where the outcome was recovery from a nonambulatory condition, defined as either rising $(32 / 37 ; 86 \%)$ or survival $(5 / 37 ; 14 \%)$. Definitions not based on symptomology were frequent in the literature $(186 / 379 ; 49 \%)$, the most common of which was defining the criteria for diagnosing the nonambulatory outcome as "clinical signs" without further defining what these included
(76/186; 41\%). Other potentially ambiguous definitions of nonambulatory outcomes included recovery following calcium treatment as a diagnostic criterion for milk fever $(25 / 186 ; 13 \%)$, nonresponse to calcium therapy as a diagnostic criterion for downer cow syndrome $(6 / 186$; $3 \%)$, veterinary diagnosis $(17 / 186 ; 9 \%)$, producer diagnosis $(9 / 186 ; 5 \%)$, symptoms unattributable to other disorders $(11 / 186 ; 6 \%)$, and treatment records $(14 / 186$; $8 \%)$.

\section{Randomized Controlled Trials}

Thirty-eight percent of the nonambulatory dairy cow literature in the present review consisted of randomized controlled trials $(144 / 379)$, most of which were parallel in structure $(139 / 144 ; 97 \%)$, with only a small number of crossover studies (5/144; $3 \%$ ). Randomization strategy was reported in only half of the controlled trials (74/144), of which $15 \%$ reported their method of randomization, (11/74), 14\% reported use of a nonrandom method (10/74), and $72 \%$ mentioned randomization without specifying the method used $(53 / 74)$.

Table 2 provides an overview of trends in the study of prevention (116/144) and treatment (28/144) of nonambulatory conditions in dairy cattle between 1940 and 2020. Briefly, the rate of publications investigating prevention of nonambulatory outcomes increased dramatically in the 1970s and 1980s, where the focus was primarily vitamin D supplementation (20 publications); the number of prevention publications per decade was fairly consistent through to 2020, although interest shifted to use of anionic salts as a method of prevention from 1990 to 2020 (19 publications).

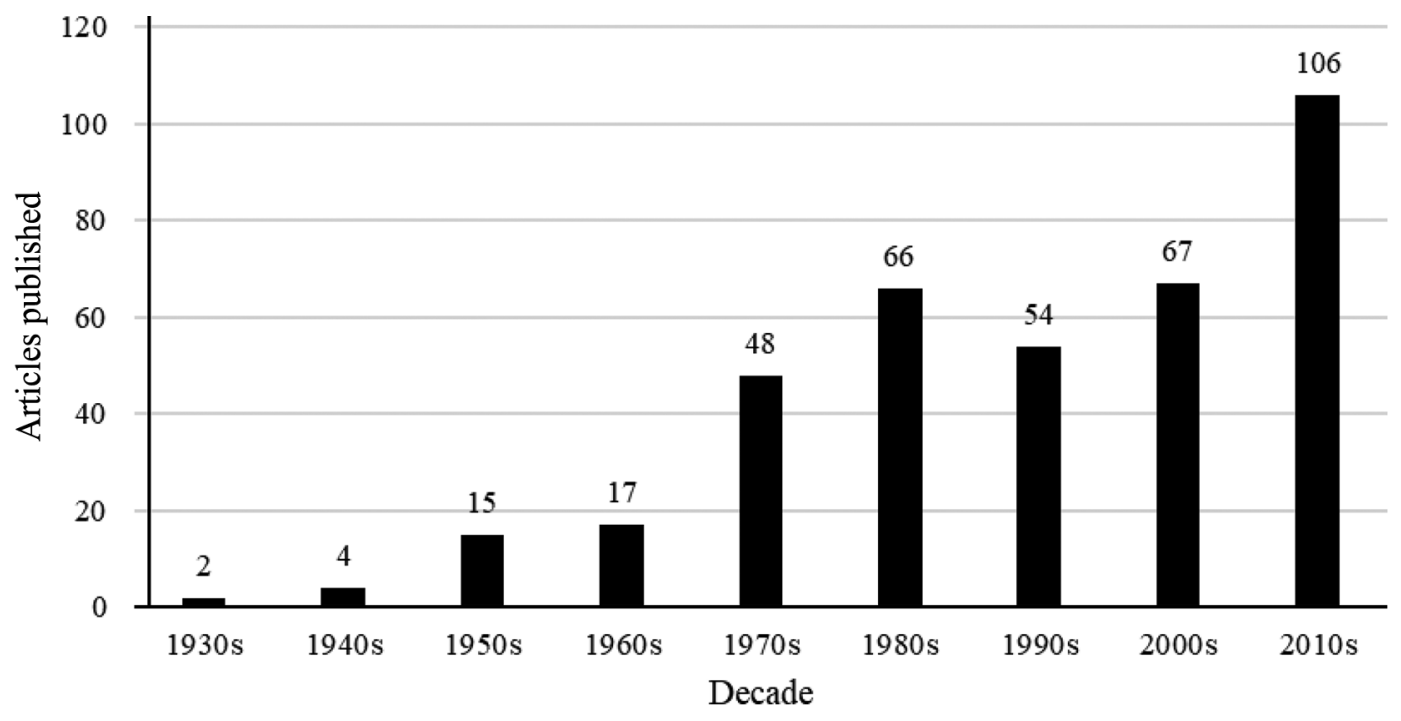

Figure 2. Distribution of the frequency of analytical studies involving nonambulatory dairy cattle included in the present scoping review (n $=379$ ) that were published each decade between 1930 and 2020. The 2010s included 3 articles published in 2020. 


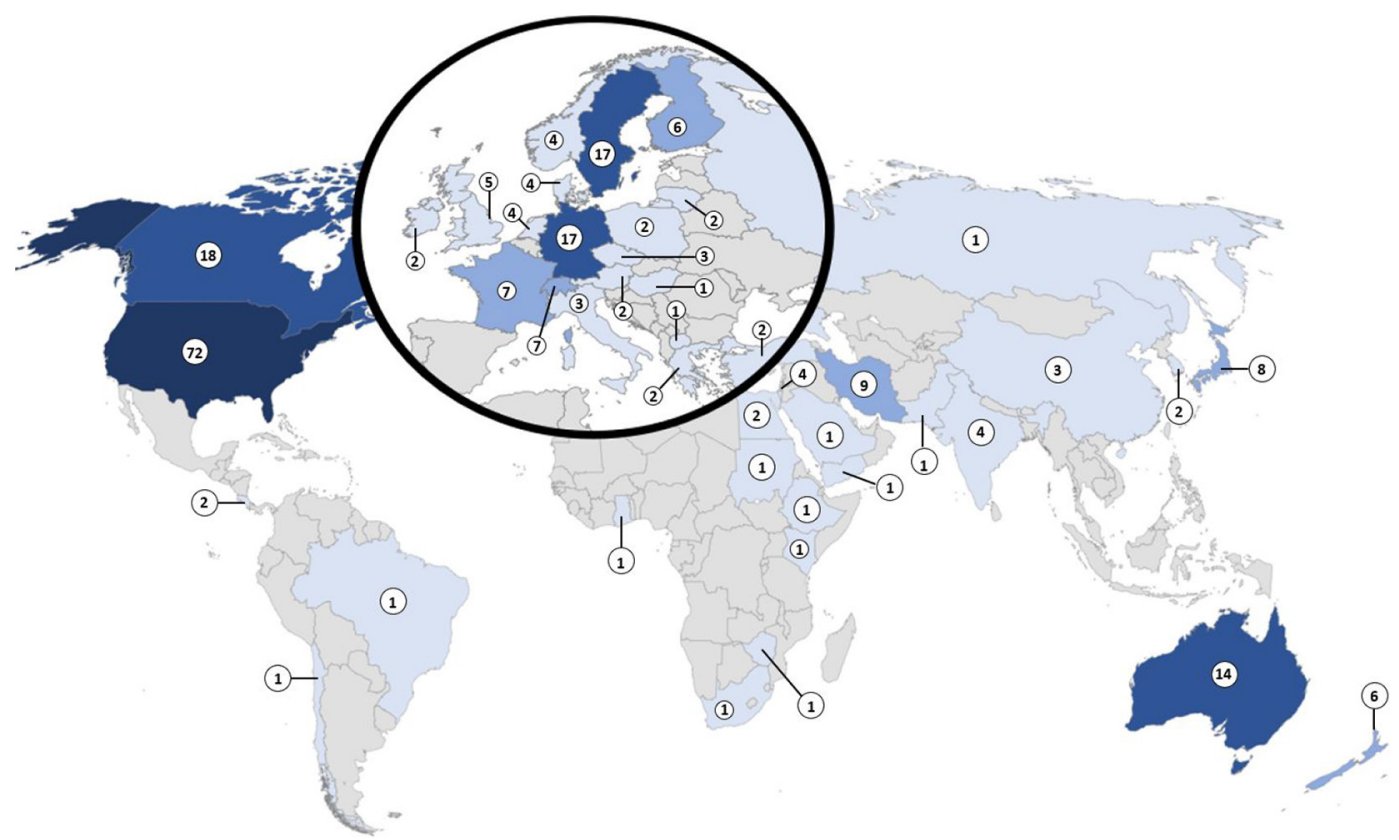

Figure 3. Distribution of countries in which analytical studies involving nonambulatory dairy cattle took place among publications in the present scoping review that reported this information $(\mathrm{n}=247)$.

The most common preventative interventions were supplementation of vitamin D $(27 / 116 ; 23 \%)$ and calcium $(25 / 116 ; 22 \%)$ as well as anionic salts $(22 / 116$; $19 \%$ ), and manipulation of the forage type or ration nutrient composition $(17 / 116 ; 15 \%)$. Other interventions included the following: phosphorus supplementation $(8 / 116 ; 7 \%)$, parathyroid hormone supplementation $(5 / 116 ; 4 \%)$, a low calcium diet prepartum $(5 / 116$; $4 \%$ ), supplementation of minerals in addition to calcium and phosphorus $(5 / 116 ; 4 \%)$, zeolite $(4 / 116 ; 3 \%)$, ammonium chloride $(3 / 116 ; 3 \%)$, and prepartum milking $(2 / 116 ; 2 \%)$. One study each examined supplementation of vitamins other than vitamin $\mathrm{D}$, mastectomy, low phosphorus prepartum, manipulation of dry-period length, housing, and supplementation of hydrochloric acid, ketoprofen, EDTA, Glycoline, somatotropin, flumethasone, and disodium ethane-l-hydroxy-1,1diphosphonate.

Treatment of nonambulatory outcomes comprised $19 \%$ of the controlled trial literature found in the pres-

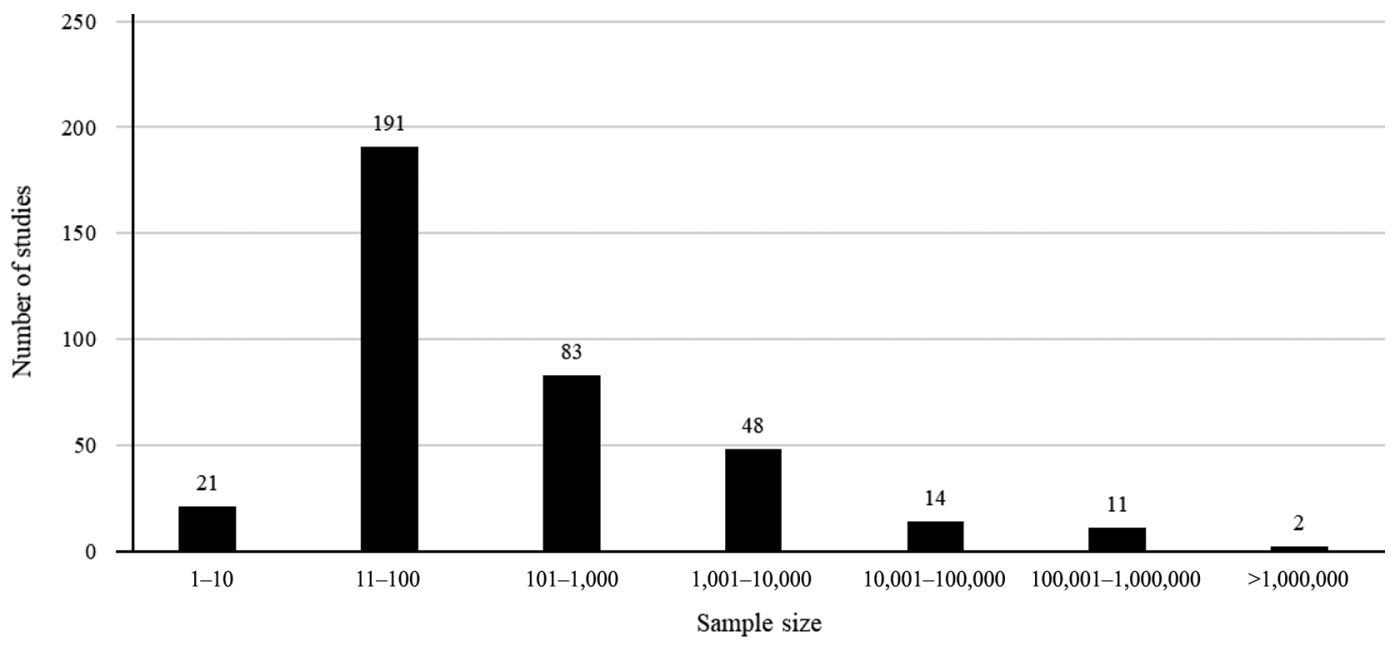

Figure 4. Distribution of the reported sample size among the studies included in the present scoping review that reported this information $(\mathrm{n}=370)$. 
ent review (28/144), with almost all studies involving administration of calcium in some form to one of the treatment groups $(26 / 28 ; 93 \%)$. The most common calcium compounds investigated were calcium borogluconate $(21 / 26 ; 81 \%)$ and calcium chloride $(3 / 26 ; 12 \%)$. The effectiveness of calcium combined with other compounds was also common in the treatment literature, including magnesium $(10 / 28 ; 36 \%)$, phosphorus $(12 / 28$; $43 \%)$, glucose $(4 / 28 ; 14 \%)$, and vitamin D $(1 / 28 ; 4 \%)$. Last, 3 studies investigated naloxone as a treatment for nonambulatory disorders in dairy cattle $(3 / 28 ; 11 \%)$.

Of the controlled trial literature in the present review, $28 \%(41 / 144)$ reported the period of risk, after which cattle having not experienced the outcome would be deemed outcome negative. Of the 14 studies reporting the risk period of recovery, this duration ranged from $0.2 \mathrm{~h}$ to $720 \mathrm{~h}$, with a mean of $66.5 \mathrm{~h}$ (SD: $190.5 \mathrm{~h}$ ). Of the 27 studies reporting the risk period for becoming nonambulatory, this period of observation ranged from $0.25 \mathrm{~d}$ to $84 \mathrm{~d}$, with a mean of $25.2 \mathrm{~d}$ (SD: $27.1 \mathrm{~d}$ ).

\section{Observational Studies}

Sixty-two percent of the studies included in the present review were observational studies (235/379). The observational literature consisted predominantly of cohort studies $(148 / 235 ; 63 \%)$ and case-control studies $(58 / 235 ; 25 \%)$, as well as a small number of cross-sectional studies $(29 / 235 ; 12 \%)$. The majority of the cohort studies were prospective $(128 / 148 ; 86 \%)$, whereas $14 \%$ were retrospective (20/148).

Becoming nonambulatory or recovering from a nonambulatory condition was a measured outcome in 196 of the 235 observational studies in the present scoping review. The outcome in $84 \%(165 / 196)$ of these studies was becoming nonambulatory. The most commonly measured risk factors for becoming nonambulatory were blood calcium $(73 / 165 ; 44 \%)$, phosphorus $(53 / 165$; $32 \%)$, and magnesium $(42 / 165 ; 25 \%)$. Other measured blood parameters measured as risk factors for becom- ing nonambulatory included glucose $(19 / 165 ; 12 \%)$; minerals other than calcium, phosphorus, and magnesium $(18 / 165 ; 11 \%)$; blood lipid compounds $(17 / 165$; $10 \%)$; blood cells and clotting factors $(16 / 165 ; 10 \%)$; metabolites of energy metabolism $(14 / 165 ; 8 \%)$; vitamin D $(13 / 165 ; 8 \%)$; concentration $(13 / 165 ; 8 \%)$ and activity $(7 / 165 ; 4 \%)$ of enzymes such as creatine kinase and aspartate aminotransferase; and miscellaneous blood compounds not easily grouped by structure or function $(21 / 165 ; 13 \%)$. Phenotypic features of cattle that were commonly measured as risk factors for becoming nonambulatory included parity $(35 / 165 ; 21 \%)$, breed $(22 / 165 ; 13 \%)$, milk production $(19 / 165 ; 12 \%)$, age $(14 / 165 ; 8 \%)$, and BCS $(9 / 165 ; 5 \%)$. Other commonly measured risk factors included season and year of calving $(19 / 165 ; 12 \%)$, compounds in urine $(13 / 165$; $8 \%)$, heritability $(14 / 165 ; 8 \%)$, and feed composition $(14 / 165 ; 8 \%)$. Hormones involved in calcium regulation such as calcitonin and parathyroid hormone were measured risk factors for becoming nonambulatory in $7 \%$ of studies $(12 / 165)$, and hormones not involved in calcium regulation such as insulin and cortisol were also risk factors in $7 \%$ of studies $(11 / 165)$. Other notable risk factors for becoming nonambulatory that were measured in the literature included nonmetabolic disease $(13 / 165 ; 8 \%)$, metabolic disease $(13 / 165 ; 8 \%)$, housing $(10 / 165 ; 6 \%)$, and herd size $(9 / 165 ; 5 \%)$. A comprehensive list of risk factors for becoming nonambulatory measured in the observational literature is presented in Table 3.

Within the observational literature, recovery from a nonambulatory condition was the outcome in 31 studies. The most common potential risk factors for recovery (prognostic factors) examined in the literature were the concentration of blood minerals including calcium $(9 / 31 ; 29 \%)$, phosphorus $(9 / 31 ; 29 \%)$, magnesium $(6 / 31 ; 19 \%)$, and other blood minerals $(5 / 31$; $16 \%)$. Other blood parameters measured as prognostic factors included blood enzymes concentration (6/31; $19 \%)$, enzyme activity $(5 / 31 ; 16 \%)$, metabolites of

Table 2. Number of publications per decade investigating prevention and treatment of nonambulatory dairy cattle, as well as the frequency of those specifically investigating vitamin $\mathrm{D}$ as a prevention or treatment, calcium as a prevention or treatment, and DCAD as a prevention

\begin{tabular}{|c|c|c|c|c|c|c|c|}
\hline Decade & $\begin{array}{l}\text { Vitamin D } \\
\text { prevention }\end{array}$ & $\begin{array}{l}\text { Vitamin D } \\
\text { treatment }\end{array}$ & $\begin{array}{c}\mathrm{Ca} \\
\text { prevention }\end{array}$ & $\begin{array}{c}\mathrm{Ca} \\
\text { treatment }\end{array}$ & $\begin{array}{c}\text { DCAD } \\
\text { prevention }\end{array}$ & $\begin{array}{c}\text { Total } \\
\text { prevention }\end{array}$ & $\begin{array}{c}\text { Total } \\
\text { treatment }\end{array}$ \\
\hline $1940 \mathrm{~s}$ & 1 & 0 & 0 & 0 & 0 & 3 & 0 \\
\hline $1950 \mathrm{~s}$ & 1 & 0 & 2 & 1 & 0 & 6 & 1 \\
\hline $1970 \mathrm{~s}$ & 9 & 1 & 3 & 4 & 0 & 22 & 4 \\
\hline $1980 \mathrm{~s}$ & 11 & 0 & 4 & 2 & 3 & 23 & 2 \\
\hline $1990 \mathrm{~s}$ & 2 & 1 & 4 & 4 & 7 & 15 & 4 \\
\hline Total & 27 & 3 & 25 & 26 & 22 & 114 & 28 \\
\hline
\end{tabular}


energy metabolism $(5 / 31 ; 16 \%)$, serum sugars $(4 / 31$; $13 \%)$, blood cells and clotting factors $(4 / 31 ; 13 \%)$, and miscellaneous blood compounds not easily grouped by structure or function $(7 / 31 ; 23 \%)$. Nonhematological prognostic factors present in the literature included duration of recumbency $(7 / 31 ; 23 \%)$, weight $(4 / 31 ; 13 \%)$, age $(4 / 31 ; 13 \%)$, parity $(3 / 31 ; 10 \%)$, and quality of nursing care $(1 / 31 ; 3 \%)$.

Being nonambulatory was measured as a risk factors in 53 studies, with death or euthanasia being the most commonly measured outcome $(11 / 53 ; 21 \%)$. Disorders of the transition period were measured in $21 \%$ of studies $(11 / 53)$, including metritis $(9 / 53 ; 17 \%)$, retained placenta $(8 / 53 ; 15 \%)$, ketosis $(8 / 53 ; 15 \%)$, and dystocia $(6 / 53 ; 11 \%)$. Other disorders measured as outcomes downstream of cattle becoming nonambulatory included mastitis $(7 / 53 ; 13 \%)$, displaced abomasum $(5 / 53$; $9 \%)$, disorders of the digestive tract $(4 / 53 ; 8 \%)$, and infectious disease $(2 / 53 ; 4 \%)$. Measures of productivity including milk yield $(7 / 53 ; 13 \%)$ and fertility $(6 / 53$; $11 \%)$ were also measured outcomes following cattle becoming nonambulatory.

Table 3. Frequency (number of papers) of risk factors measured in the observational literature in which the outcome of interest was a nonambulatory condition in dairy cattle $(\mathrm{n}=196)$, subdivided by those where the outcome was becoming nonambulatory $(\mathrm{n}=165)$, and those where only nonambulatory dairy cattle were enrolled and the outcome was recovery from a nonambulatory disorder $(\mathrm{n}=31)$

\begin{tabular}{|c|c|c|c|}
\hline Risk factor & Becoming nonambulatory & Recovery & Total \\
\hline Blood (Ca) & 73 & 9 & 82 \\
\hline Blood (Pi) & 53 & 9 & 62 \\
\hline Blood (Mg) & 42 & 6 & 48 \\
\hline Parity & 35 & 3 & 38 \\
\hline Miscellaneous blood compounds & 21 & 7 & 28 \\
\hline Breed & 22 & 1 & 23 \\
\hline Blood (sugar) & 19 & 4 & 23 \\
\hline (Other blood minerals) & 18 & 5 & 23 \\
\hline Blood cells and clotting factors & 16 & 4 & 20 \\
\hline Year and season of calving & 19 & 0 & 19 \\
\hline Blood (enzyme) & 13 & 6 & 19 \\
\hline Blood (lipid compounds) & 17 & 2 & 19 \\
\hline Blood (metabolites of energy metabolism) & 14 & 5 & 19 \\
\hline Milk yield & 19 & 0 & 19 \\
\hline Age & 14 & 4 & 18 \\
\hline Metabolic disease & 13 & 4 & 17 \\
\hline Nonmetabolic disease & 13 & 2 & 15 \\
\hline Urinalysis & 13 & 2 & 15 \\
\hline Feeding & 14 & 0 & 14 \\
\hline Heritability & 14 & 0 & 14 \\
\hline Blood (vitamin D) & 13 & 1 & 14 \\
\hline Ca regulation hormones & 12 & 1 & 13 \\
\hline Weight or BCS & 9 & 4 & 13 \\
\hline Blood enzyme activity & 7 & 5 & 12 \\
\hline Miscellaneous blood properties & 10 & 2 & 12 \\
\hline Housing factors & 10 & 1 & 11 \\
\hline Milk fever prevention measures & 9 & 2 & 11 \\
\hline Non-Ca-regulating hormones & 11 & 0 & 11 \\
\hline Management practices & 8 & 2 & 10 \\
\hline Herd size & 9 & 0 & 9 \\
\hline Duration of recumbency & 1 & 7 & 8 \\
\hline Miscellaneous herd-level factors & 6 & 1 & 7 \\
\hline Nonblood/urine (mineral) & 6 & 1 & 7 \\
\hline Time relative to calving & 5 & 2 & 7 \\
\hline Miscellaneous activity/regulation & 6 & 0 & 6 \\
\hline Calf factors & 5 & 0 & 5 \\
\hline Dry-period length & 5 & 0 & 5 \\
\hline Fertility & 5 & 0 & 5 \\
\hline Rumen parameters & 3 & 2 & 5 \\
\hline Region & 3 & 1 & 4 \\
\hline Cardiovascular parameters & 2 & 2 & 4 \\
\hline Milk or colostrum composition & 4 & 0 & 4 \\
\hline Transport variables & 4 & 0 & 4 \\
\hline Position when attended & 1 & 3 & 4 \\
\hline Rectal temperature & 2 & 1 & 3 \\
\hline Rainfall & 2 & 0 & 2 \\
\hline Pasture length & 1 & 0 & 1 \\
\hline
\end{tabular}


Fourteen of the observational studies mentioned above analyzed being nonambulatory as both an outcome and a risk factor. Factors enabling a nonambulatory state to act as both a risk factor and an outcome included path analysis $(2 / 14 ; 14 \%)$, treating a nonambulatory episode as a risk factor for recurrence in the following lactation $(3 / 14 ; 21 \%)$, measuring milk fever as a risk factor for downer cow syndrome $(3 / 14 ; 21 \%)$, and performing analysis on outcomes downstream of becoming nonambulatory, as well as upstream factors such as age, parity, or season $(6 / 14 ; 43 \%)$. Upstream factors most commonly measured in these studies included parity $(7 / 14 ; 50 \%)$, metabolic disease $(6 / 14$; $43 \%)$, and nonmetabolic disease $(4 / 14 ; 29 \%)$, whereas the most common downstream factors were metritis $(5 / 14 ; 36 \%)$, ketosis $(4 / 14 ; 29 \%)$, mastitis $(4 / 14 ; 29 \%)$, and left displaced abomasum $(4 / 14 ; 29 \%)$.

\section{DISCUSSION}

\section{Highly Investigated Topics}

There are several areas of the down cow literature that have been well explored. Based on the results of the present review, there appears to be a strong body of literature investigating prevention and treatment of metabolic nonambulatory conditions in dairy cattle. This finding could indicate that metabolic causes of recumbency such as hypocalcemia are of particular relevance to the dairy industry compared with other causes, or possibly that metabolic mechanisms of recumbency have been recognized for longer, and have had more time to accumulate research (Allen and Davies, 1981; Cox and Onapito, 1986). Moreover, a particularly interesting finding was that the most intensely studied prevention among the included literature appears to have changed over time. Contributing factors could include industrial application catalyzing interest in a topic, or development of theories inspiring new avenues of research, the latter possibly explaining why early works on dietary cation anion balance followed seminal works on strong ion theory (Stewart, 1983; Oetzel et al., 1991). Furthermore, there was a large body of observational literature investigating hematological risk factors for dairy cattle becoming nonambulatory. A potential explanation for the emphasis on hematological risk factors is that concentration of blood minerals such as calcium and magnesium are an important part of diagnosing the cause of recumbency. Alternatively, analyzing blood samples could enable researchers to measure a large panel of blood components, which could explain why many of the included articles measured several blood components. Last, duration of recumbency and serum concentration of minerals and creatine kinase were frequently investigated prognostic indicators. Taken together, this suggested that although metabolic causes of recumbency currently dominate the literature, there is potential for interest to shift toward less dominant topics such as biomarkers of nonmetabolic recumbency such as creatine kinase.

\section{Gaps in the Literature}

The present review identified 31 studies in which prognostic indicators for the recovery of nonambulatory dairy cattle were investigated, representing $8 \%(31 / 379)$ of the literature. The most common of these prognostic indicators were hematological parameters, which may not be applicable on farm due to lack of equipment. As mentioned above, the reliance on hematological factors may be due to the convenience of measuring a large panel of blood compounds. Hematological factors may be used to differentiate metabolic recumbency, which was supported by the fact that calcium was a common prognostic indicator among the included literature. Nonhematological prognostic factors in the literature included age $(4 / 31)$, parity $(3 / 31)$, breed of cattle $(1 / 31)$, time relative to calving that the cow became nonambulatory $(2 / 31)$, and whether the cow was in sternal or lateral recumbency (3/31). Although the accuracy of these prognostic indicators was beyond the scope of this review, they have value because they can be accessed easily, quickly, inexpensively, and reasonably accurately in a producer's records, or directly observed. An additional topic that could potentially represent a gap in the literature is recumbency experienced by cattle who are being transported for slaughter, which was the topic of 4 included studies. Although loading of nonambulatory animals for slaughter is prohibited in regions including Canada (Government of Canada, 2019) and the European Union (EC No 1/2005), complex welfare issues can arise when an animal becomes nonambulatory while in transit, as regulations often prohibit unloading of these animals unless rendered unconscious or killed on the truck (CFIA, 2020). Investigation into factors that prevent cattle from becoming nonambulatory during transport could improve the welfare experienced by these animals, and potentially benefit producers, transport companies, and slaughter facilities. Last, none of the included studies measured behavioral or physiological measures of welfare, representing a potential gap in the literature.

Of the studies that investigated treatment of nonambulatory conditions, almost all used calcium compounds. A contributing factor could be that in addition to calcium being used to treat hypocalcemia (Sasaki et 
al., 2013; Braun et al., 2016), nonresponse to calcium therapy is often used as a diagnostic criterion for causes of recumbency other than hypocalcemia (Björkman et al., 1994; Oikawa and Katoh, 2002; Labonté et al., 2018). There is also prognostic value in nonresponse to calcium therapy in a clinical setting, as this could indicate that secondary muscular damage has occurred, which affects likelihood of recovery (Cox, 1988; Poulton et al., 2016a). Provided that such cattle are not experiencing trauma such as fractures or luxation, the course of treatment should shift toward physiotherapeutic measures aimed at reducing the effect of secondary muscular damage (Cox and Farmsworth, 1998). The present review identified 2 studies in which such therapeutic measures were investigated as a means to relieve pressure damage, one of which used flotation therapy (Burton et al., 2009), whereas the other used slings (Samantara et al., 2012). During flotation therapy, a nonambulatory cow is supported by buoyancy in a tank of warm water (Dahlberg, 2012). This allows for increased perfusion of muscle tissue through relief of pressure damage, warm water, and controlled use of leg muscles (Van Metre et al., 1996; Burton et al., 2009). In addition to treating secondary muscular damage, the controlled use of leg muscles facilitated by flotation therapy can also treat calving paralysis (Roberts, 2017). An alternative to flotation therapy is to intermittently assist a nonambulatory cow to stand with the use of slings while massaging the limbs with warm water, which can provide similar benefits with respect to treating secondary muscular damage through increased circulation (Raghavendran et al., 2020). Although 2 studies investigating the topic of physiotherapeutic treatment of nonambulatory conditions were identified in this scoping review, there appeared to be more literature to this topic than the review would suggest. Although some of these were case studies (Raghavendran et al., 2020), there were analytical studies that were not included (Stojkov et al., 2016), possibly reflecting a limitation in the methodology of this scoping review at the literature search or screening phase.

Although prognostic factors, welfare indicators, and treatment of nonmetabolic causes of recumbency were covered in a small number of articles included in this review, it is somewhat subjective to indicate that they represent a gap in the literature. A small number of studies may provide compelling evidence that could lead some to consider additional research on the topic unnecessary. However, further research may be merited on some of these topics, provided that the existing literature is not deemed sufficient to provide a complete understanding of the topic. Additionally, there may be more literature covering these topics that used terminology outside our search string, as considerable variability was found in the terminology used among the studies that were included.

\section{Nonambulatory Terminology}

The underlying conditions that cause dairy cattle to present as nonambulatory can be broadly grouped into metabolic causes such as hypocalcemia and hypomagnesemia, and "downer cow syndrome," a term that captures essentially all nonmetabolic causes of recumbency (Cox and Onapito, 1998). However, the wide variety of additional terminology has made matters confusing. "Milk fever" and "parturient paresis" are often used interchangeably in the literature to describe dairy cattle that are unable to stand due to acute hypocalcemia during the transition period (Deiner et al., 2012; Bani Hassan et al., 2018). However, although "parturient paresis" implies clinical signs, there are instances in which "milk fever" is used simply to describe hypocalcemia without specifying that affected cattle are in a nonambulatory state (Ducusin et al., 2003). Conversely, although "milk fever" implies hypocalcemia, there are instances in which the term "parturient paresis" is used to simply to describe cattle that are nonambulatory around the time of calving, not necessarily due to metabolic imbalance (Bendixen et al., 1986; Bendixen et al., 1987). This could prove problematic when comparing works written by authors who have a different understanding of these terms, and could lead to incorrect conclusions being drawn if the reader and the author have a different understanding of the condition under study. The literature regarding nonambulatory dairy cattle is further complicated by inconsistent use of the terms "downer cow" and "downer cow syndrome." "Downer cow syndrome" is often distinguished from other nonambulatory disorders in that calcium is an ineffective treatment (Björkman et al., 1994; Oikawa and Katoh, 2002; Labonté et al., 2018). In the present review, nonresponse to calcium therapy was used as a diagnostic criterion in $13 \%(6 / 47)$ of the studies that used "downer cow syndrome" to define their nonambulatory condition. This leads to uncertainty as to whether the remaining $87 \%(41 / 47)$ are using the traditional definition of downer cow syndrome (nonresponse to calcium therapy), another definition entirely, or are using the term interchangeably with milk fever or parturient paresis. Although guidance regarding the correct nomenclature to categorize nonambulatory cattle based on symptoms and etiology has been published (Fenwick, 1969; Cox and Onapito, 1998), these reviews involve terminology that is not commonly used in recent literature such as "creeper cow," and the dif- 
ferentiation of alert and nonalert downer cows. Hence, there is a clear need for the publication of an updated statement on the use of terms to describe nonambulatory dairy cattle.

A critical step toward achieving clear and consistent language in the literature concerning nonambulatory dairy cattle is to ensure that authors further define all nonambulatory terms they use with explicit diagnostic criteria. Definitions of nonambulatory terms were sometimes made clearer through the use of qualifiers such as "recovery following calcium treatment" (25) and "nonresponse to calcium treatment" (6), which help distinguish nonambulatory terms that differ based on these criteria. However, qualifiers such as "recovery following calcium treatment" were sometimes used as a stand-alone definition (13), leaving the reader to speculate what state these cattle were recovering from. Furthermore, some studies used potentially unreliable criteria in their diagnosis of nonambulatory conditions, such as producer diagnosis (9) and treatment records (14). These criteria rely on the producer having complete and accurate records, and the ability to diagnose and differentiate types of nonambulatory disorders. Criteria such as these may be unavoidable in retrospective studies, but should only be used when direct observation is not possible.

The present review found variability in terminology used to describe nonambulatory conditions and diagnostic criteria for these conditions. Although such variability in terminology may have little consequence in a clinical setting, it could present problems when comparing literature in which the terms are used inconsistently. Moreover, future systematic reviews on the topic of nonambulatory dairy cattle should consider this variability in terminology when developing a search string.

\section{Limitations}

Relevant literature could have been missed during the literature search or screening phase of the review due to not being published in English, not having an available full text, or using terms to describe nonambulatory cattle that were not present in our search string. The goal of the search string was to capture analytical studies in which recumbency in dairy cattle was a measured variable. The search string focused primarily on nonambulatory terms, whereas terms indirectly related to nonambulatory dairy cattle such as specific preventions and treatments were not included. Although this helped achieve the goal of capturing the terminology used to describe recumbency among metabolic, nonmetabolic, infectious disease, and trauma literature, reviewer burden was greatly increased. Moreover, this could have limited the search sensitivity with respect to secondary recumbency, which is when the reason a cow is recumbent shifts from the proximate cause to secondary muscular damage after prolonged recumbency (Cox and Onapito, 1998). The assumption was made that literature concerning both primary and secondary recumbency would use one of the recumbency terms in our search string if recumbency was a measured variable. However, as this was an assumption, inclusion of terms such as "pressure damage," "rehabilitation," or specific preventions or treatments of secondary recumbency may have increased the sensitivity of the search string with respect to the secondary recumbency literature. The exclusion of non-English articles has been found to influence the conclusions drawn from meta-analyses (Grégoire et al., 1995); although the present review did not draw conclusions based on statistical analysis, it is possible that the exclusion of 148 non-English articles during the full-text screening phase could have accounted for gaps in the literature. Of the articles that passed the abstract screening stage $(1,544), 350$ articles were excluded because their full text could not be located. However, a characterization of the information available on these 350 articles revealed that $32 \%$ $(111 / 350)$ were published in non-English journals, and $17 \%(59 / 350)$ were only 1 page in length, both of which could potentially have resulted in exclusion of these articles. Furthermore, $70 \%(245 / 350)$ of these articles were published before 1990 and may not be available in an electronic format.

\section{CONCLUSIONS}

This body of literature is predominantly observational, measuring hematological parameters as risk factors for dairy cattle becoming nonambulatory. A smaller number of studies examined prognostic indicators for recovery from nonambulatory conditions, an area of research that may require more attention. One-third of the included literature comprised randomized controlled trials, of which the majority studied prevention of nonambulatory outcomes. This literature was very homogeneous, primarily focusing on calcium as a treatment, and preventions including vitamin $\mathrm{D}$, calcium, and anionic salts. Inconsistencies were found in the terms used to describe nonambulatory dairy cattle, which was further complicated by poor reporting of diagnostic criteria used to define these terms. There is a need for guidance regarding correct usage of the array of terms describing nonambulatory cattle, as well as extension efforts to communicate proper usage of these terms to veterinarians, producers, and researchers. 


\section{ACKNOWLEDGMENTS}

The authors thank Derrick Knill, Andrea Bajus, Kineta Cousins, Jennifer Dunn, and Matt Van Camp (University of Guelph, Guelph, ON, Canada) for assisting in the reviewing process. This work was funded through the Ontario Graduate Scholarship program (University of Guelph, Guelph, ON, Canada). The authors have not stated any conflicts of interest.

\section{REFERENCES}

Allen, W. M., and D. C. Davies. 1981. Milk fever, hypomagnesaemia and the downer cow syndrome. Br. Vet. J. 137:435-441. https:// doi.org/10.1016/S0007-1935(17)31644-5.

Arksey, H., and L. O'Malley. 2005. Scoping studies: Towards a methodological framework. Int. J. Soc. Res. Methodol. 8:19-32. https:/ /doi.org/10.1080/1364557032000119616.

Bani Hassan, E., M. Nouri, S. Vogrin, and M. Pyman. 2018. Can neutral dietary cation-anion difference (DCAD) decrease occurrence of clinical periparturient hypocalcaemia in dairy cattle? Aust. Vet. J. 96:269-273. https://doi.org/10.1111/avj.12712.

Bar, D., and E. Ezra. 2005. Effects of common calving diseases on milk production in high yielding dairy cows. Isr. J. Vet. Med. 60:106-111.

Bendixen, P. H., B. Vilson, I. Ekesbo, and D. B. Åstrand. 1986. Disease frequencies of tied zero-grazing dairy cows and of dairy cows on pasture during summer and tied during winter. Prev. Vet. Med. 4:291-306. https://doi.org/10.1016/0167-5877(86)90011-5.

Bendixen, P. H., B. Vilson, I. Ekesbo, and D. B. Åstrand. 1987. Disease frequencies in dairy cows in Sweden. III. Prev. Vet. Med. 5:87-97. https://doi.org/10.1016/0167-5877(87)90014-6.

Björkman, C., G. Jonsson, and R. Wroblewski. 1994. Concentrations of sodium, potassium, calcium, magnesium and chlorine in the muscle cells of downer cows and cows with parturient paresis. Res. Vet. Sci. 57:53-57. https://doi.org/10.1016/0034-5288(94)90081-7.

Blonde, G., and B. Leder. 2016. Handling Down Cows. WI Veterinarian Medical Association. Accessed May 1, 2021. https://fyi.uwex .edu/dairy/files/2016/03/downer-cow-factsheet.pdf.

Bradley, C. H. 1993. Copper poisoning in a dairy herd fed a mineral supplement. Can. Vet. J. 34:287-292.

Braun, U., K. Feige, G. Schweizer, and A. Pospischil. 2005. Clinical findings and treatment of 30 cattle with botulism. Vet. Rec. 156:438-441. https://doi.org/10.1136/vr.156.14.438.

Braun, U., D. Grob, and M. Hässig. 2016. Treatment of cows with parturient paresis using intravenous calcium and oral sodium phosphate. Schweiz. Arch. Tierheilkd. 158:615-622. https://doi.org/10 $.17236 /$ sat00081.

Burton, A. J., D. V. Nydam, T. L. Ollivett, and T. J. Divers. 2009. Prognostic indicators for nonambulatory cattle treated by use of a flotation tank system in a referral hospital: 51 cases (1997-2008). J. Am. Vet. Med. Assoc. 234:1177-1182. https://doi.org/10.2460/ javma.234.9.1177.

Canadian Food Inspection Agency. 2020. Health of Animals Regulations: Part XII: Transport of Animals-Regulatory Amendment: Interpretive Guidance for Regulated Parties. Accessed Apr. 28, 2021. https://inspection.canada.ca/animal-health/humane-transport/ health-of-animals-regulations-part-xii/eng/1582126008181/ 1582126616914\#а7.

Caple, I. W. 1987. Unravelling mineral and metabolic problems in dairy herds: Australian Advances in Veterinary Science. Pages 19-21 in Proc. 64th Annu. Conf. Australian Veterinary Association. AVA.

Cox, V. S. 1988. Nonsystemic causes of the downer cow syndrome. Vet. Clin. North Am. Food Anim. Pract. 4:413-433. https://doi.org/10 .1016/S0749-0720(15)31057-4.
Cox, V. S., and R. J. Farmsworth. 1998. Prevention and treatment of down cows: A continuum. Pages 167-169 in Proc. 31st Annu. Conf. American Association of Bovine Practitioners. AABP.

Cox, V. S., C. J. McGrath, and S. E. Jorgensen. 1982. The role of pressure damage in pathogenesis of the downer cow syndrome. Am. J. Vet. Res. 43:26-31.

Cox, V. S., and J. S. Onapito. 1986. An update on the downer cow syndrome. Bov. Pract. 21:195. https://doi.org/10.21423/bovine -vol0no21p195-199.

Cox, V. S., and J. S. Onapito. 1998. The many causes of down cows. Pages 164-166 in Proc. 31st Annu. Conf.: American Association of Bovine Practitioners. AABP.

Dahlberg, J. 2012. Flotation therapy for downer cows. Veterinary Medicine Program, Department of Clinical Sciences, Swedish University of Agricultural Sciences, Alnarp, Sweden.

DeGaris, P. J., and I. J. Lean. 2009. Milk fever in dairy cows: A review of pathophysiology and control principles. Vet. J. 176:58-69. https: //doi.org/10.1016/j.tvjl.2007.12.029.

Deiner, C., M. Reiche, D. Lassner, D. Grienitz, S. Twardziok, A. Moesch, P. Wenning, and H. Martens. 2012. Allelic variations in coding regions of the vitamin $\mathrm{D}$ receptor gene in dairy cows and potential susceptibility to periparturient hypocalcaemia. J. Dairy Res. 79:423-428. https://doi.org/10.1017/S0022029912000465.

Ducusin, R. J. T., M. Nishimura, T. Sarashina, Y. Uzuka, S. Tanabe, and M. Otani. 2003. Phagocytosis of bovine blood and milk polymorphonuclear leukocytes after ozone gas administration in vitro. J. Vet. Med. Sci. 65:535-539. https://doi.org/10.1292/jvms .65 .535 .

Esslemont, R. J., and M. A. Kossaibati. 1996. Incidence of production diseases and other health problems in a group of dairy herds in England. Vet. Rec. 139:486-490. https://doi.org/10.1136/vr.139 .20.486.

Fenwick, D. C. 1969. The downer cow syndrome. Aust. Vet. J. 45:184188. https://doi.org/10.1111/j.1751-0813.1969.tb01926.x.

Fikadu, W., T. Dechassa, A. Nejash, and M. A. Wahid. 2016. Milk fever and its economic consequences in dairy cows. Glob. Vet. $16: 441-452$

Government of Canada. 2019. Health of Animals Act, Part 12, 139. Accessed Mar. 29, 2021. https://inspection.canada.ca/animal -health/humane-transport/health-of-animals-regulations-part-xii/ eng/1582126008181/1582126616914.

Green, A. L., J. E. Lombard, L. P. Garber, B. A. Wagner, and G. W. Hill. 2008. Factors associated with occurrence and recovery of nonambulatory dairy cows in the United States. J. Dairy Sci. 91:2275-2283. https://doi.org/10.3168/jds.2007-0869.

Grégoire, G., F. Derderian, and J. LeLorier. 1995. Selecting the language of the publications included in a meta-analysis: Is there a tower of babel bias? J. Clin. Epidemiol. 48:159-163. https://doi .org/10.1016/0895-4356(94)00098-B.

Hibbs, J. W. 1950. Milk fever (parturient paresis) in dairy cows-A review. J. Dairy Sci. 33:758-789. https://doi.org/10.3168/jds.S0022 -0302(50)91966-7.

Khan, A., M. H. Mushtaq, A. W. Khan, M. Chaudhry, and A. Hussain. 2015. Descriptive epidemiology and seasonal variation in prevalence of milk fever in KPK (Pakistan). Glob. Vet. 14:472477. https://doi.org/10.5829/idosi.gv.2015.14.04.93172.

Labonté, J., J. Dubuc, J.-P. Roy, and S. Buczinski. 2018. Prognostic value of cardiac troponin I and L-lactate in blood of dairy cows affected by downer cow syndrome. J. Vet. Intern. Med. 32:484-490. https://doi.org/10.1111/jvim.14874.

Mee, J. F. 1993. Incidence of periparturient clinical hypocalcaemia on six research dairy farms. Moorepark Research and Development Division.

Mulon, P. Y. 2013. Management of long bone fractures in cattle. In Pract. 35:265-271. https://doi.org/10.1136/inp.f2869.

Oetzel, G. R., M. J. Fettman, D. W. Hamar, and J. D. Olson. 1991. Screening of anionic salts for palatability, effects on acid-base status, and urinary calcium excretion in dairy cows. J. Dairy Sci. 74:965-971. https://doi.org/10.3168/jds.S0022-0302(91)78245-3. 
Oikawa, S., and N. Katoh. 2002. Decreases in serum apolipoprotein B-100 and A-I concentrations in cows with milk fever and downer cows. Can. J. Vet. Res. 66:31-34.

Poulton, P. J., A. D. Fisher, P. D. Mansell, and M. F. Pyman. 2019. Clinical findings from 104 cases of calving paralysis in dairy cows from Gippsland, Australia. N. Z. Vet. J. 67:214-218. https://doi .org/10.1080/00480169.2019.1602086.

Poulton, P. J., A. L. Vizard, G. A. Anderson, and M. F. Pyman. 2016a. Importance of secondary damage in downer cows. Aust. Vet. J. 94:138-144. https://doi.org/10.1111/avj.12437.

Raghavendran, V. B., S. Suresh Babu, S. Rajasokkappan, V. Alex Albert, and N. Tamilselvan. 2020. Successful recovery of Holstein Friesian crossbred prepartum downer: A case report. Pharma Innov. 9(8S):102-103. https://doi.org/10.22271/tpi.2020.v9.i8Sc .5070 .

Roberts, J. N. 2017. Flotation therapy for management of calving paralysis following dystocia in a Piedmontese cow. Clin. Theriogenology 9:435.

Samantara, S., R. Rout, S. Nayak, P. C. Dey, and J. Mohanty. 2012. Downed bovines and its rehabilitation using physiotherapeutic slings - A study in 40 animals. Intas Polivet 13:297-303.

Sasaki, K., K. Sasaki, Y. Sato, B. Devkota, K. Furuhama, and N. Yamagishi. 2013. Response of Holstein cows with milk fever to first treatment using two calcium regimens: A retrospective clinical study. J. Vet. Med. Sci. 75:373-376. https://doi.org/10.1292/ jvms.12-0352.

Schmidt, L. M., and P. C. Gotzsche. 2005. Of mites and men: Reference bias in narrative review articles: A systematic review. J. Fam. Pract. 54:334-338.

Stewart, P. A. 1983. Modern quantitative acid-base chemistry. Can. J. Physiol. Pharmacol. 61:1444-1461. https://doi.org/10.1139/y83 $-207$.

Stojkov, J., D. M. Weary, and M. A. G. von Keyserlingk. 2016. Nonambulatory cows: Duration of recumbency and quality of nursing care affect outcome of flotation therapy. J. Dairy Sci. 99:20762085. https://doi.org/10.3168/jds.2015-10448.

Thilsing-Hansen, T., R. J. Jorgensen, and S. Ostergaard. 2002. Milk fever control principles: A review. Acta Vet. Scand. 43:1-19. https: //doi.org/10.1186/1751-0147-43-1.

Tricco, A. C., E. Lillie, W. Zarin, K. K. O'Brien, H. Colquhoun, D. Levac, D. Moher, M. D. J. Peters, T. Horsley, L. Weeks, S. Hempel, E. A. Akl, C. Chang, J. McGowan, L. Stewart, L. Hartling, A. Aldcroft, M. G. Wilson, C. Garritty, S. Lewin, C. M. Godfrey, M. T. Macdonald, E. V. Langlois, K. Soares-Weiser, J. Moriarty, T. Clifford, O. Tuncalp, and S. E. Straus. 2018. PRISMA extension for scoping reviews (PRISMA-ScR): Checklist and explanation. Ann. Intern. Med. 169:467-473. https://doi.org/10.7326/M18-0850.

USDA. 2018. Dairy 2014: Health and Management Practices on U.S. Dairy Operations, 2014. Accessed Sep. 9, 2021. https://www .aphis.usda.gov/aphis/ourfocus/animalhealth/monitoring-and -surveillance/nahms/NAHMS_Dairy_Studies.

Van Metre, D. C., G. St. Jean, and J. Vestweber. 1996. Flotation therapy for downer cows. Kansas Agric. Exp. Stn. Res. Reports. $2: 38-41$.

Yadav, G. P., V. Sangwan, and A. Kumar. 2019. Comparative occurrence pattern of fractures in cattle and buffaloes. Vet. World 12:1154-1159. https://doi.org/10.14202/vetworld.2019.1154-1159.

\section{ORCIDS}

W. J. McFarlane (ㅇ https://orcid.org/0000-0001-7486-2314

D. L. Renaud (D) https://orcid.org/0000-0002-3439-3987

C. N. Reedman (1) https://orcid.org/0000-0003-3904-0993

T. F. Duffield (1) https://orcid.org/0000-0001-6035-4669

M. B. Van Camp (1D https://orcid.org/0000-0003-4473-0024

C. B. Winder () https://orcid.org/0000-0002-7314-3657 